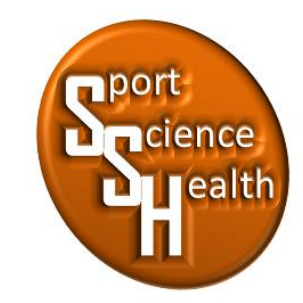

ISSN 2715-3886

\title{
Pengembangan Perangkat Pembelajaran Bola Basket Berbasis Aplikasi Articulate Storyline
}

\author{
Dinar Akbarul Rozak ${ }^{1 \star}$, Lokananta Teguh Hari Wiguno ${ }^{2}$, Ari Wibowo Kurniawan ${ }^{3}$, Mu'arifin $^{4}$ \\ 1,2,3,4Jurusan Pendidikan Jasmani, Kesehatan dan Rekreasi, Fakultas IImu Keolahragaan, \\ Universitas Negeri Malang, Jalan Semarang No 5, Malang, Jawa Timur, 65145, Indonesia \\ *Penulis koresponden: akbarul.dinar@gmail.com, 082232462449
}

Artikel diterima: 3 Februari 2021; direvisi: 15 April 2021; disetujui: 21 April 2021

\begin{abstract}
The purpose of the research and development is to develop the learning of a basketball-based applications articulate storyline. Methods in research and development using the research model Lee and Owen. The results of the research and product development learning tools basketball on the trials of a small group $84 \%$ while for the test a large group of $86 \%$. There is a conclusion in a research and development namely product development is fit for use in learning activities.
\end{abstract}

Keyword: learning device, basketball, working group of teachers, elementary school

\begin{abstract}
Abstrak: Tujuan dalam penelitian dan pengembangan ini yaitu untuk mengembangkan perangkat pembelajaran bola basket berbasis aplikasi articulate storyline. Metode dalam penelitian dan pengembangan ini menggunakan model penelitian Lee and Owen. Hasil dari penelitian dan pengembangan produk perangkat pembelajaran bola basket pada uji coba kelompok kecil $84 \%$ sedangkan untuk uji coba kelompok besar $86 \%$. Terdapat kesimpulan dalam penelitian dan pengembangan ini yaitu produk pengembangan layak digunakan pada kegiatan pembelajaran.
\end{abstract}

Kata kunci: perangkat pembelajaran, bola basket, kelompok kerja guru, sekolah dasar

\section{PENDAHULUAN}

Pendidikan merupakan hal penting yang terprogram yang memiliki tujuan untuk menumbuhkan kapasitas dalam setiap diri peserta didik. Salah satu tujuan dari pendidikan nasional yaitu meluaskan potensi dalam diri peserta didik agar berpikir secara rasional dan memiliki akhlak mulia dalam perspektif pancasila (Soeprapto, 2013). Pendidikan adalah suatu proses dalam memudahkan siswa agar dapat melakukan proses dengan hasil yang optimal, dengan harapan berkembang semaksimal mungkin, selaras pada keunggulan yang dipunyai, dan pedoman nilai yang ada dalam masyarakat. Oleh sebab itu, pendidik harus menciptakan situasi yang mendukung bagi perkembangan anak. Pendidik harus menciptakan situasi yang mendukung bagi perkembangan anak. Nantinya dalam pendidikan akan terjadi proses perkembangan pribadi atau watak manusia menuju pribadi yang layak. Oleh sebab itu, pendidikan jasmani memiliki peranan penting didalamnya.

Pendidikan jasmani, olahraga, dan kesehatan ialah mata pelajaran yang sangat berkontribusi terhadap pembangunan Sumber Daya Manusia (SDM) (Adi \& Fathoni, 2019, 2020a, 2020b, 2020c; Fathoni, 2018). Pendidikan jasmani, olahraga, dan kesehatan dalam perspektif pendidikan harus diprioritaskan dalam aspek latihan jasmani dan olahraga kesehatan agar meningkatkan kualitas sehat dinamis dan koordinasi serta 
kemampuan motorik yang baik (Bangun, 2016). Pendidikan jasmani, olahraga, dan kesehatan telah menjadi bagian integral dari program pendidikan keseluruhan. Pada materi pendidikan jasmani, olahraga, dan kesehatan termuat sebagian materi pembelajaran didalamnya. Salah satu materi yang termuat pada pembelajaran di sekolah yaitu materi bola basket. Bahkan pembelajaran bola basket ditemukan pada kompetensi inti dan dasar pelajaran pendidikan jasmani, olahraga, dan kesehatan Sekolah Dasar kelas VI yang disebutkan bahwa:

Tabel 1. Kompetensi Inti \& Kompetensi Dasar Pendidikan Jasmani, Olahraga, dan Kesehatan Sekolah Dasar Kelas VI (Kementerian Pendidikan Nasional, 2018)

\begin{tabular}{|c|c|}
\hline Kompetensi Inti Pengetahuan Kelas VI & Kompetensi Inti Keterampilan Kelas VI \\
\hline $\begin{array}{l}\text { Memahami pengetahuan faktual dan } \\
\text { konseptual dengan cara mengamati, } \\
\text { menanya dan mencoba berdasarkan rasa } \\
\text { ingin tahu tentang dirinya, makhluk.ciptaan } \\
\text { Tuhan dan kegiatannya, dan benda-benda } \\
\text { yang dijumpainya di rumah, di sekolah dan di } \\
\text { tempat bermain. }\end{array}$ & $\begin{array}{l}\text { Menyajikan pengetahuan faktual dan konseptual } \\
\text { dalam bahasa yang jelas, sistematis, logis dan } \\
\text { kritis, dalam karya yang estetis, dalam gerakan } \\
\text { yang mencerminkan anak sehat, dan dalam } \\
\text { tindakan yang mencerminkan perilaku anak } \\
\text { beriman dan berakhlak mulia. }\end{array}$ \\
\hline Kompetensi Dasar Pengetahuan Kelas VI & Impilan Kelas VI \\
\hline $\begin{array}{l}\text { Memahami variasi dan kombinasi gerak dasar } \\
\text { lokomotor, non-lokomotor, dan manipulatif } \\
\text { dengan kontrol yang baik dalam permainan } \\
\text { bola besar sederhana dan atau tradisional }\end{array}$ & $\begin{array}{l}\text { Mempraktikkan variasi dan kombinasi gerak dasar } \\
\text { lokomotor, non-lokomotor, dan manipulatif dengan } \\
\text { kontrol yang baik dalam permainan bola besar } \\
\text { sederhana dan atau tradisional }\end{array}$ \\
\hline
\end{tabular}

Hal tersebut dapat digunakan pendidik didalam pembelajaran untuk mengembangkan perangkat pembelajaran pada materi bola basket. Bola basket adalah suatu bagian dari banyaknya olahraga yang memiliki tujuan memperoleh skor sebanyak mungkin yang dilakukan dengan berusaha memasukkan bola pada ring yang berada pada daerah lawan. Terdapat 9 model pembelajaran yang dapat dilakukan bagi anak SD kelas atas, yaitu: (1) saling mengejar dengan dribble, (2) dribble pada lingkaran, (3) dribble ular kencang, (4) mengumpan dengan melampaui tali, (5) passing war, (6) lompat kemudian shoot, (7) mengumpan, menggiring dan menembak, (8) permainan bola basket dengan memodifikasi sarana dan prasarana, dan (9) permainan bola basket dengan memodifikasi sarana dan prasarana tanpa melakukan dribble (Walton \& Lismadiana, 2015). Permainan bola basket juga dapat bermanfaat bagi anak, diantaranya dapat meningkatkan kesehatan dan mengoptimalkan tumbuh kembang anak. Melatih anak untuk kian sportif, meningkatkan kecerdasan, membimbing anak untuk bersosialisasi, membentuk rasa percaya diri dan kerjasama. Pembelajaran yang efektif akan menghasilkan pengetahuan yang baik untuk siswa.

Pembelajaran merupakan proses pengorganisasian dengan tujuan mengembangkan kemampuan dan membangun watak peserta didik, serta mengetahui bagaimana peserta didik belajar (Munawaroh, 2020). Oleh karena itu, pembelajaran yang dilakukan sebagai usaha untuk memfasilitasi, menginisiasi, dan meninggikan intensitas dan mutu pembelajaran pada tiap pribadi siswa. Pembelajaran pada zaman sekarang dapat dikemas dengan teknologi yang ada. Mutu pendidikan dapat meningkat sejalan dengan penggunaan teknologi yang digunakan secara efektif dan efisien pada kegiatan pembelajaran (Andri, 2017). Keberadaan teknologi pada kegiatan pembelajaran sekarang dapat memudahkan peserta didik dalam menangkap materi dan meringankan guru dalam menyampaikan materi pembelajaran. Teknologi didunia pendidikan merupakan perkembangan tentang penggunaan audiovisual dan perkembangan program belajar dalam penyelenggaraan pendidikan.

Penggunaan media dengan memanfaatkan teknologi dan dengan sekat-sekat tertentu akan memperbesar harapan siswa untuk dapat belajar lebih banyak (Christianto \& Dwiyogo, 2020; Kristiono, Dwiyogo, \& Hariadi, 2019; Kurniawan, Winarno, \& Dwiyogo, 2018; Masgumelar, Dwiyogo, \& Nurrochmah, 2019; Pambudi, Winarno, \& Dwiyogo, 2019; Rodriquez, Dwiyogo, \& Supriyadi, 2020). Dalam dunia pendidikan penggunaan media telah memberikan dampak yang positif dalam memecahkan permasalahan dalam pembelajaran (Miftah, 2013). Media pembelajaran melalui audiovisual pada saat ini merupakan salah satu yang sering digunakan dan dapat meringankan siswa ketika menerima materi yang diberikan oleh guru. Hasil temuan Fathir \& Tuasikal (2013) mengatakan pemanfaatan media pembelajaran melalui Computer Assisted Instructional (CIA) dengan menggunakan model drills pada materi travelling violation permainan bola basket 
mampu meningkatkan hasil tes kognitif siswa sebesar $66,17 \%$. Oleh sebab itu, pemilihan media dalam menyampaikan materi kepada peserta didik selayaknya disusun secara sistematis oleh pendidik. Hal itu bertujuan untuk dapat memikat peserta didik agar belajar secara efisien dan efektif dalam lingkungan belajar yang mendukung. Namun media pembelajaran tidak bisa berdiri sendiri sebagai penentu keberhasilan dalam mencapai hasil belajar yang optimal. Terdapat juga perangkat pembelajaran yang dipakai pendidik seperti alat dalam melaksanakan kegiatan mengajar.

Perangkat pembelajaran merupakan panduan wajib yang dilaksanakan oleh guru pada saat di kelas (Fitron \& Mu'arifin, 2020; Hamzah, Mu'arifin, Heynoek, Kurniawan, \& Kurniawan, 2020a; Mu'arifin, 2019). Melalui perangkat pembelajaran guru juga dapat mengevaluasi dirinya sendiri apakah perangkat pembelajaran yang telah dibuat dapat berjalan di dalam kelas. Hal tersebut sangatlah penting dalam meningkatkan profesionalitas seorang guru. Diperjelas penelitian oleh Mu'arifin, Kurniawan, \& Paulina (2018) menyimpulkan model pengembangan profesional untuk guru PJOK mampu dipakai sebagai model pelatihan guru-guru sekolah dasar PJOK. Melalui produk yang dibuat, antara lain: modul, pedoman administrasi, dan pedoman monitoring dan evaluasi. Peran guru sangat dibutuhkan dalam menyelenggarakan pendidikan untuk meningkatkan kualitas peserta didik. Kemampuan pedagogik merupakan komponen yang harus dimiliki oleh guru, apabila guru dapat memahami karakteristik siswanya nantinya dapat meringankan guru dalam menyampaikan materi yang diberikan. Terdapat juga pengaruh dari kompetensi pedagogik guru dengan Kelompok Kerja Guru (KKG) dengan kapasitas guru penjas di SD pada Kecamatan Ciamis (Rakhman \& Brata, 2018). Upaya dalam meningkatkan kinerja guru juga dilakukan dengan dibentuknya Kelompok Kerja Guru (KKG).

Dengan dibentuknya Kelompok Kerja Guru (KKG) diupayakan dapat meningkatkan kinerja guru dengan cara berinteraksi antar guru dalam satu wilayah tertentu dalam menyelesaikan masalah dan mengembangkan mutu pembelajaran. Hasil temuan Yayuk \& Prastiyowati (2019) mengatakan perlu adanya pelatihan bagi guru yang bertujuan dalam meningkatkan kompetensi dan wawasan guru terhadap perangkat pembelajaran. Penerapan workshop dalam kegiatan Kelompok Kerja Guru (KKG) juga mampu meningkatkan kompetensi guru dalam mengembangkan perangkat pembelajaran (Mufidah, 2018). Oleh sebab itu, dengan adanya Kelompok Kerja Guru (KKG) maka guru mempunyai naungan dalam menyampaikan kendala-kendala dalam pembelajaran dan kendala tersebut nantinya menjadi pembahasan dalam forum tersebut.

Berdasarkan observasi awal diperoleh data analisis kebutuhan $100 \%$ pendidik pernah mengajarkan materi bola basket, $85 \%$ tidak pernah mengembangkan Rencana Pelaksanaan Pembelajaran (RPP) yang dapat diakses secara online, $85 \%$ tidak pernah mengembangkan bahan ajar pada materi bola basket yang dapat diakses online, dan $80 \%$ tidak pernah mengembangkan soal-soal pada materi bola basket yang dapat dikerjakan secara online. Sedangkan $100 \%$ pendidik memiliki handphone dan laptop, $75 \%$ pendidik mengatakan terdapat jaringan WiFil Internet pada tempat mengajar. Hal tersebut sangat mendukung dalam menunjang pembelajaran di era sekarang. Dengan adanya percepatan teknologi yang ada sekarang diperlukan pemanfaatan teknologi pada bidang pendidikan khususnya pembelajaran PJOK.

Penggunaan aplikasi perangkat pembelajaran berbasis articulate storyline tersebut peneliti tentukan setelah melaksanakan analisis kebutuhan, agar aplikasi yang digunakan nantinya dapat bermanfaat dalam kegiatan pembelajaran. Penggunaan aplikasi nantinya dapat diakses melalui smartphone dan laptop sehingga produk tersebut dapat memudahkan guru yang tergabung dalam Kelompok Kerja Guru (KKG) PJOK Sekolah Dasar Kecamatan Mayang Kabupaten Jember dalam melakukan kegiatan pembelajaran. Harapan dengan adanya produk pengembangan tersebut yaitu dapat menciptakan suasana belajar yang baru dan memunculkan sumber belajar yang baru dalam pembelajaran pendidikan jasmani, olahraga, dan kesehatan pada jenjang Sekolah Dasar yang selama ini masih menggunakan perangkat pembelajaran dalam format print out.

\section{METODE}

Model penelitian pengembagan perangkat pembelajaran bola basket berbasis aplikasi articulate storyline berpedoman pada alur pengembangan Lee and Owens, menggunakan pendekatan Research and Development (R\&D) yang memakai tahap-tahap pengembangan sebagai berikut: 1) melaksanakan needs assessment atau analisis kebutuhan, (2) melaksanakan rancangan produk, (3) mengembangkan produk, (4) mengimplementasikan di lapangan, (5) mengevaluasi produk. Berdasarkan langkah-langkah yang dikemukakan oleh Lee and Owen tersebut merupakan suatu langkah-langkah dalam memecahkan permasalahan dalam penelitian dan nantinya dapat menghasilkan suatu produk. Peneliti dalam rancangan uji 
coba akan melaksanakan kajian berdasarkan catatan dan masukan dari lima ahli yang terdiri dari ahli pembelajaran, ahli permainan SD, ahli PJOK, ahli bola basket, ahli media dan ketika uji coba dalam kelompok kecil yang berjumlah 8 orang sedangkan dalam kelompok besar dengan jumlah 15 orang. Nantinya catatan dan saran dari para ahli dapat dijadikan pedoman dalam merevisi produk awal dalam produk peneliti. Data yang diperoleh berdasarkan tinjauan para ahli dan pelaksanaan uji coba produk yang berbentuk data kuantitatif dan kualitatif. Data kualitatif didapatkan melalui catatan dan masukan beberapa ahli. Pada dasarnya data kuantitatif didapatkan ketika uji coba kelompok kecil dan besar berupa hasil dari pengumpulan kuisioner yang berbentuk angka.

Dalam tahapan teknik menganalisis data selama melakukan penelitian yaitu menggunakan statistik deskriptif. Pengumpulan data dilakukan dengan teknik pengukuran memakai skala likert, yang dipakai dalam melihat sikap, gagasan dan persepsi individu atau suatu komunitas tertentu tentang fenomena sosial (Sugiyono, 2015). Pada instrumen di skala likert memiliki kategori respon yang mencakup sangat setuju hingga tidak setuju. Dalam kebutuhan menganalisis data kuantitatif respon dapat dibubuhkan skor yang sudah dipatenkan antara lain (1), (2), (3) dan (4).

Tabel 2. Skala Evaluasi Pernyataan (Sugiyono, 2015)

\begin{tabular}{llll}
\hline Nomor & Keterangan & Jawaban & Hasil \\
\hline 1. & Sangat Setuju & A & 4 \\
2. & Setuju & B & 3 \\
3. & Ragu-ragu & C & 2 \\
4. & Tidak Setuju & D & 1 \\
\hline
\end{tabular}

Rumus dalam mendapatkan data berbentuk deskriptif kuantitatif dengan persentase yang dikatakan Akbar \& Sriwiyana (2011), di bawah init:

$$
\mathrm{V}=\frac{\mathrm{TSEV}}{\mathrm{S}-\max } \times 100 \%
$$

\section{Keterangan:}

$\begin{array}{ll}\text { V } & \text { : Validitas } \\ \text { TSEV } & \text { : Total skor empirik validator } \\ \text { S-max } & \text { : Skor maksimal yang diharapkan } \\ 100 \% & \text { : Bilangan konstanta }\end{array}$

Kemudian sebagai memudahkan pada bagian ketepatan data hasil menganalisis persentase dapat dikaitkan pada persentase yang telah didapatkan. Penggolongan kategorisasi persentase yaitu:

Tabel 3. Parameter Status Produk (Irawan \& Japarianto, 2013)

\begin{tabular}{lll}
\hline Kriteria & Keterangan & Makna \\
\hline $75,01 \%-100,00 \%$ & Sangat Valid & Digunakan tanpa revisi \\
$50,01 \%-75,00 \%$ & Cukup Valid & $\begin{array}{l}\text { Digunakan dengan revisi } \\
\text { kecil }\end{array}$ \\
& & Tidak dapat digunakan \\
$25,01 \%-50,00 \%$ & Tidak Valid & Terlarang digunakan \\
$00,00 \%-25,00 \%$ & Sangat Tidak Valid & \\
\hline
\end{tabular}

\section{HASIL}

Disajikan data pada bahasan ini mencakup data dari: 1) justifikasi ahli pembelajaran, 2) justifikasi ahli permainan SD, 3) justifikasi ahli PJOK, 4) justifikasi ahli media, 5) validasi ahli bola basket, 6) uji coba kelompok kecil, 7) uji coba kelompok besar. 
Tabel 4. Hasil Analisis Data pada Ahli Pembelajaran

\begin{tabular}{clcl}
\hline No. & \multicolumn{1}{c}{ Perspektif } & $\%$ & Kategori \\
\hline 1. & Kejelasan & 80 & Sangat Valid \\
2. & Ketepatan & 75 & Cukup Valid \\
3. & Kemudahan & 75 & Cukup Valid \\
\hline & Rata-rata & 77 & Sangat Valid \\
\hline
\end{tabular}

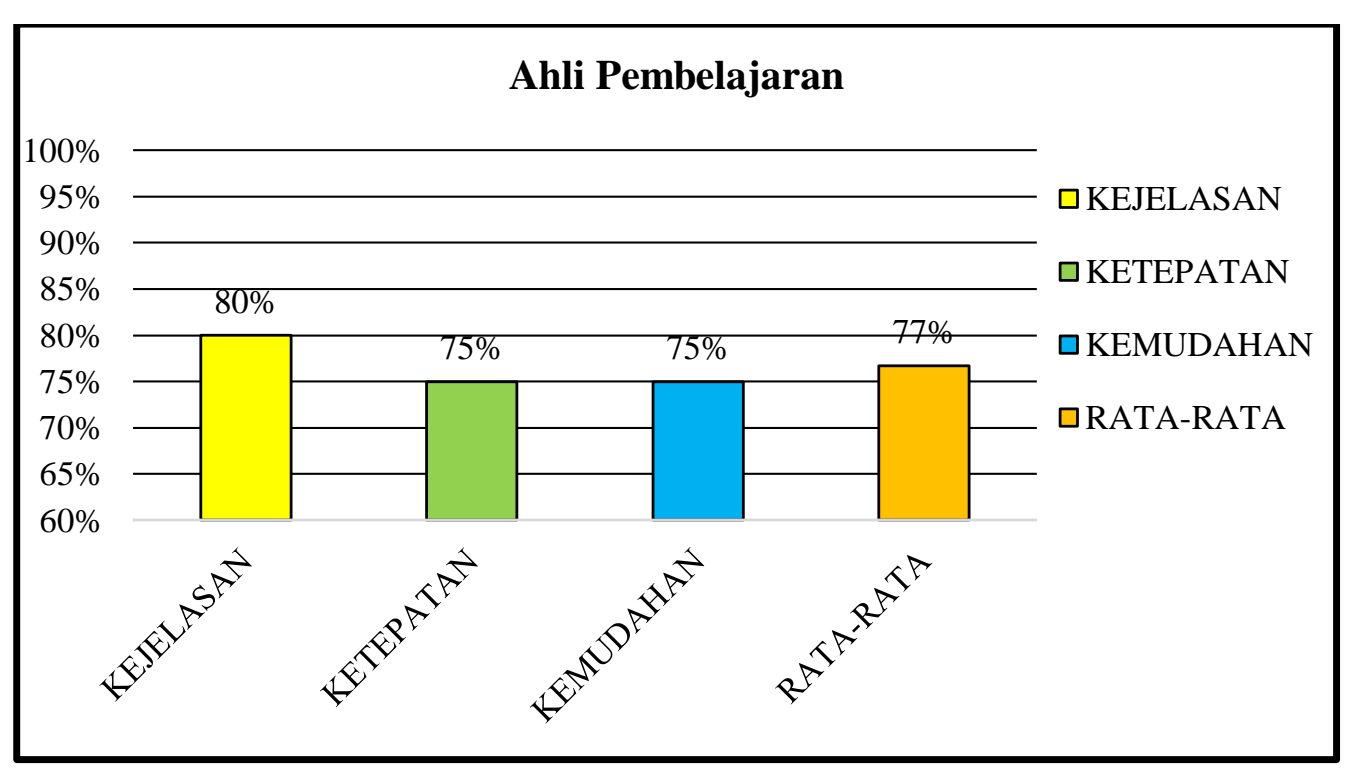

Gambar 1. Diagram Bagian Justifikasi Ahli Pembelajaran

Bersumber pada hasil menganalisis perolehan data yang didapatkan melalui ahli pembelajaran sebesar $77 \%$ hasil itu diperoleh dengan berlandaskan pedoman-pedoman yang telah dibuat. Tahap selanjutnya dengan mengkonversikan hasil tersebut kedalam tabel kategorisasi kelayakan yang mengindikasikan bahwa produk yang dikembangkan mendapatkan kategori sangat valid dan layak diimplementasikan dalam uji coba kelompok.

Tabel 5. Hasil Analisis Data pada Ahli PJOK

\begin{tabular}{clcl}
\hline No. & \multicolumn{1}{c}{ Perspektif } & $\%$ & Kategori \\
\hline 1. & Kejelasan & 100 & Sangat Valid \\
2. & Ketepatan & 89 & Sangat Valid \\
3. & Kemudahan & 75 & Cukup Valid \\
4. & Kesesuaian & 75 & Cukup Valid \\
& Rata-rata & 85 & Sangat Valid \\
\hline
\end{tabular}




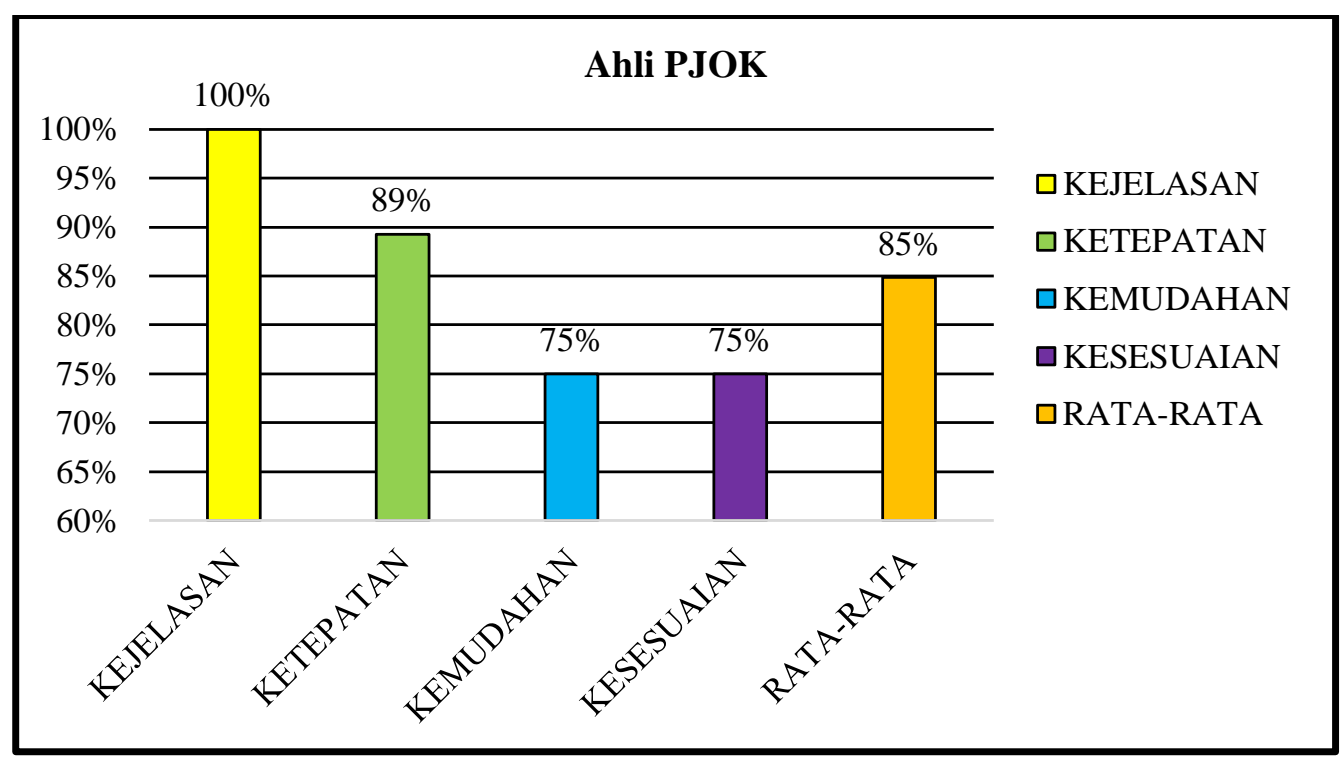

Gambar 2. Diagram Bagian Justifikasi Ahli PJOK

Bersumber pada hasil menganalisis perolehan data yang didapatkan melalui ahli PJOK sebesar $85 \%$ hasil itu diperoleh dengan berlandaskan pedoman-pedoman yang telah dibuat. Tahap selanjutnya dengan mengkonversikan hasil tersebut kedalam tabel kategorisasi kelayakan yang mengindikasikan bahwa produk yang dikembangkan mendapatkan kategori sangat valid dan layak diimplementasikan dalam uji coba kelompok.

Tabel 6. Hasil Analisis Data pada Ahli Permainan SD

\begin{tabular}{clcl}
\hline No. & \multicolumn{1}{c}{ Perspektif } & $\%$ & Kategori \\
\hline 1. & Kejelasan & 100 & Sangat Valid \\
2. & Ketepatan & 93 & Sangat Valid \\
3. & Kemudahan & 100 & Sangat Valid \\
4. & Kesesuaian & 100 & Sangat Valid \\
& Rata-rata & 98 & Sangat Valid \\
\hline
\end{tabular}

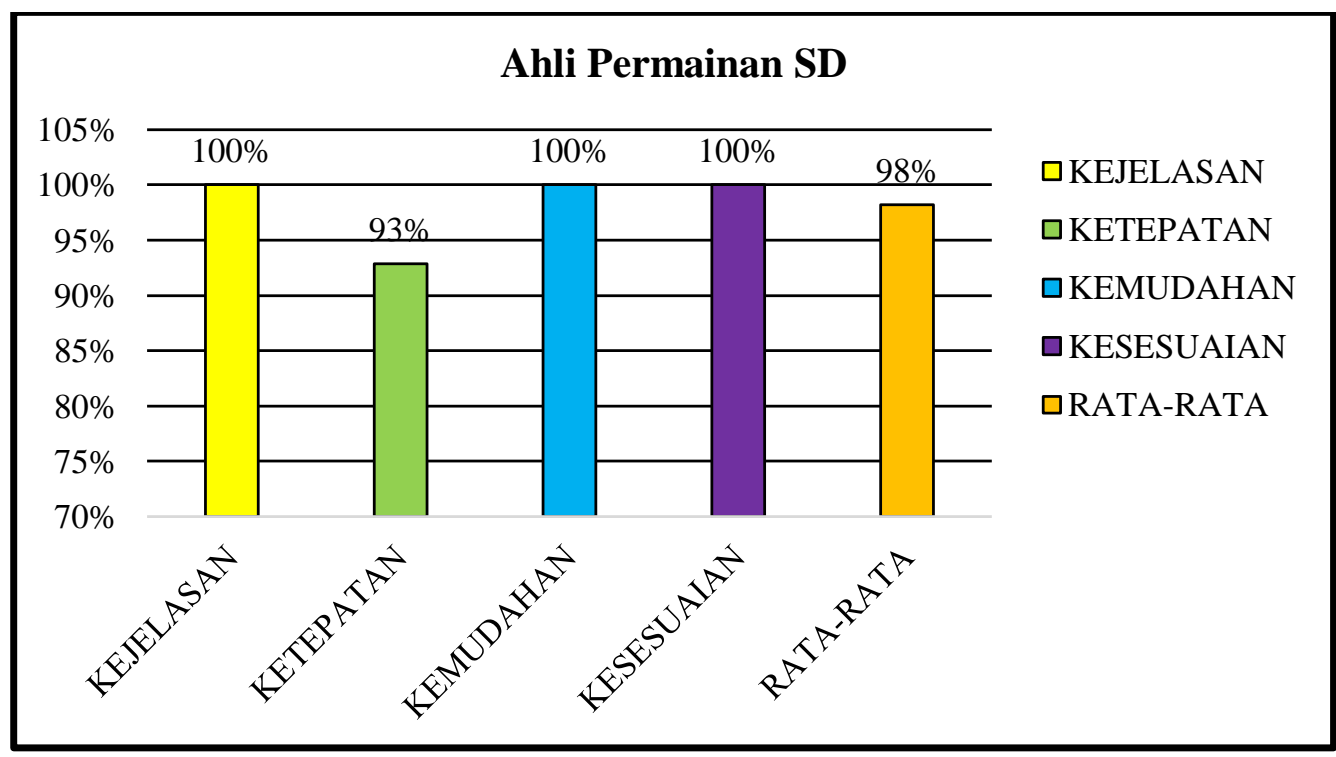

Gambar 3. Diagram Bagian Justifikasi Ahli Permainan SD

Bersumber pada hasil menganalisis perolehan data yang didapatkan melalui ahli permainan SD sebesar $98 \%$ hasil itu diperoleh dengan berlandaskan pedoman-pedoman yang telah dibuat. Tahap selanjutnya dengan mengkonversikan hasil tersebut kedalam tabel kategorisasi kelayakan yang mengindikasikan bahwa produk 
yang dikembangkan mendapatkan kategori sangat valid dan layak diimplementasikan dalam uji coba kelompok.

Tabel 7. Hasil Analisis Data Ahli Media

\begin{tabular}{clcl}
\hline No. & \multicolumn{1}{c}{ Aspek } & $\%$ & Kategori \\
\hline 1. & Kejelasan & 90 & Sangat Valid \\
2. & Kelengkapan & 100 & Sangat Valid \\
3. & Kemudahan & 100 & Sangat Valid \\
4. & Kemenarikan & 100 & Sangat Valid \\
5. & Kesesuaian & 98 & Sangat Valid \\
6. & Ketepatan & 100 & Sangat Valid \\
& Rata-rata & 98 & Sangat Valid \\
\hline
\end{tabular}

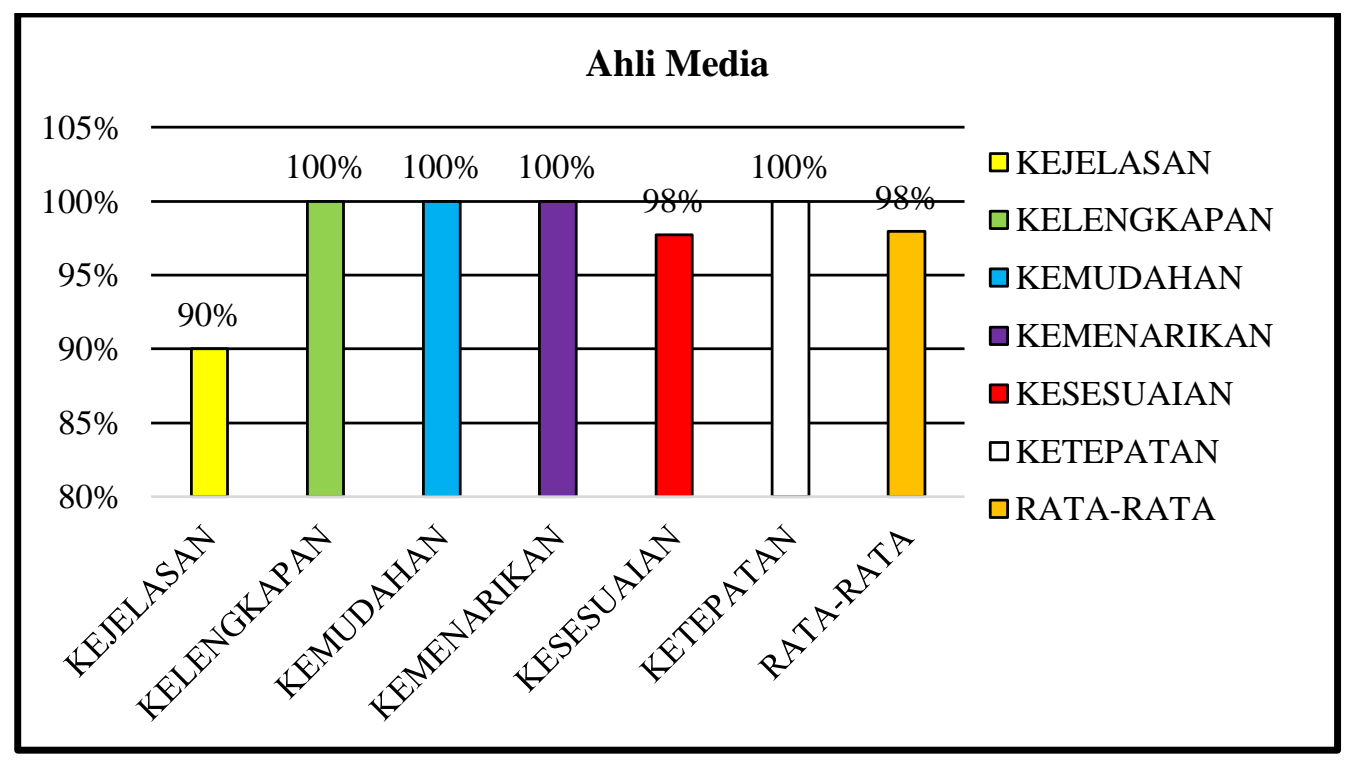

Gambar 4. Diagram Bagian Justifikasi Ahli Media

Bersumber pada hasil menganalisis perolehan data yang didapatkan melalui ahli media sebesar $98 \%$ hasil itu diperoleh dengan berlandaskan pedoman-pedoman yang telah dibuat. Tahap selanjutnya dengan mengkonversikan hasil tersebut kedalam tabel kategorisasi kelayakan yang mengindikasikan bahwa produk yang dikembangkan mendapatkan kategori sangat valid dan layak diimplementasikan dalam uji coba kelompok.

Tabel 8. Hasil Analisis Data Ahli Bola Basket

\begin{tabular}{clcc}
\hline No. & \multicolumn{1}{c}{ Aspek } & $\%$ & Kategori \\
\hline 1. & Kejelasan & 75 & Cukup Valid \\
2. & Ketepatan & 75 & Cukup Valid \\
3. & Kemudahan & 75 & Cukup Valid \\
4. & Kemenarikan & 75 & Cukup Valid \\
5. & Kesesuaian & 75 & Cukup Valid \\
\multicolumn{2}{r}{ Rata-rata } & 75 & Cukup Valid \\
\hline
\end{tabular}




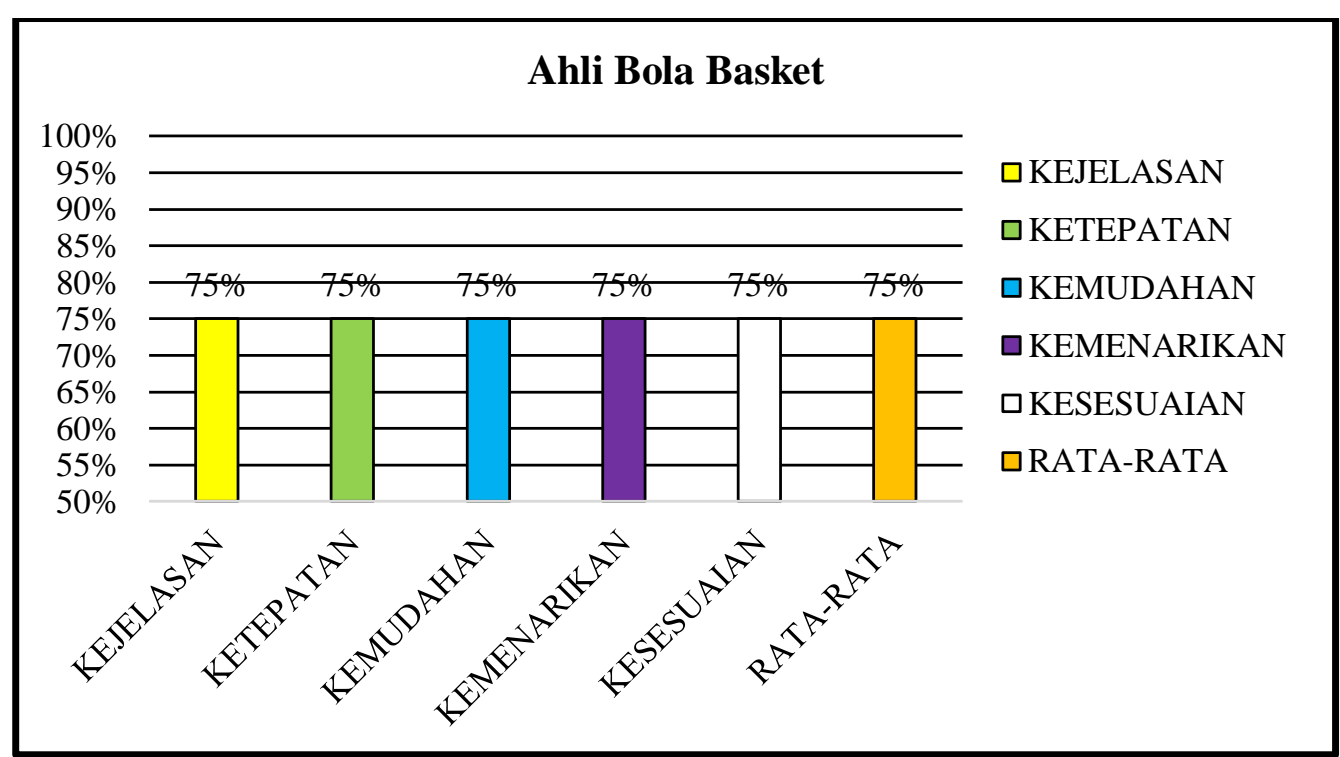

Gambar 5. Diagram Bagian Justifikasi Ahli Bola Basket

Bersumber pada hasil menganalisis perolehan data yang didapatkan melalui ahli bola basket sebesar $75 \%$ hasil itu diperoleh dengan berlandaskan pedoman-pedoman yang telah dibuat. Tahap selanjutnya dengan mengkonversikan hasil tersebut kedalam tabel kategorisasi kelayakan yang mengindikasikan bahwa produk yang dikembangkan mendapatkan kategori cukup valid dan layak diimplementasikan dalam uji coba kelompok.

Tabel 9. Hasil Analisis Data pada Uji Coba Kelompok Kecil

\begin{tabular}{clcl}
\hline No. & \multicolumn{1}{c}{ Aspek } & $\%$ & Kategori \\
\hline 1. & Kejelasan & 84 & Sangat Valid \\
2. & Kemenarikan & 85 & Sangat Valid \\
3. & Kemudahan & 87 & Sangat Valid \\
4. & Kegunaan & 86 & Sangat Valid \\
5. & Kesesuaian & 80 & Sangat Valid \\
\multicolumn{2}{r}{ Rata-rata } & 84 & Sangat Valid \\
\hline
\end{tabular}

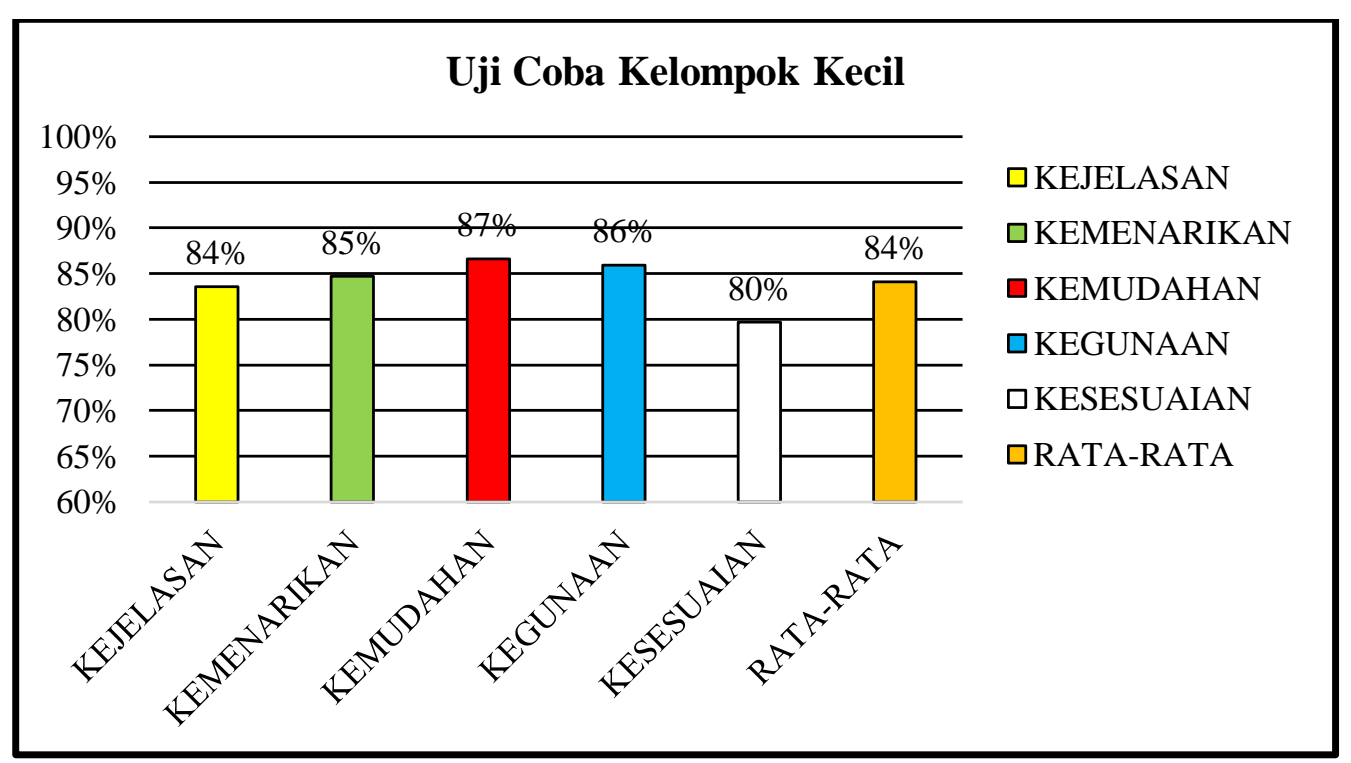

Gambar 6. Diagram Bagian Uji Coba Kelompok Kecil

Bersumber pada hasil menganalisis perolehan data yang didapatkan pada uji coba kelompok kecil sebesar $84 \%$, hasil itu diperoleh dengan berlandaskan pedoman-pedoman yang telah dibuat. Tahap selanjutnya dengan mengkonversikan hasil tersebut kedalam tabel kategorisasi kelayakan yang mengindikasikan bahwa 
produk yang dikembangkan mendapatkan kategori kriteria sangat valid dan layak diimplementasikan dalam pembelajaran.

Tabel 10. Hasil Analisis Data Uji Coba Kelompok Besar

\begin{tabular}{clcc}
\hline No. & \multicolumn{1}{c}{ Aspek } & $\%$ & Kategori \\
\hline 1. & Kejelasan & 86 & Sangat Valid \\
2. & Kemenarikan & 85 & Sangat Valid \\
3. & Kemudahan & 85 & Sangat Valid \\
4. & Kegunaan & 88 & Sangat Valid \\
5. & Kesesuaian & 84 & Sangat Valid \\
\multicolumn{2}{c}{ Rata-rata } & 86 & Sangat Valid \\
\hline
\end{tabular}

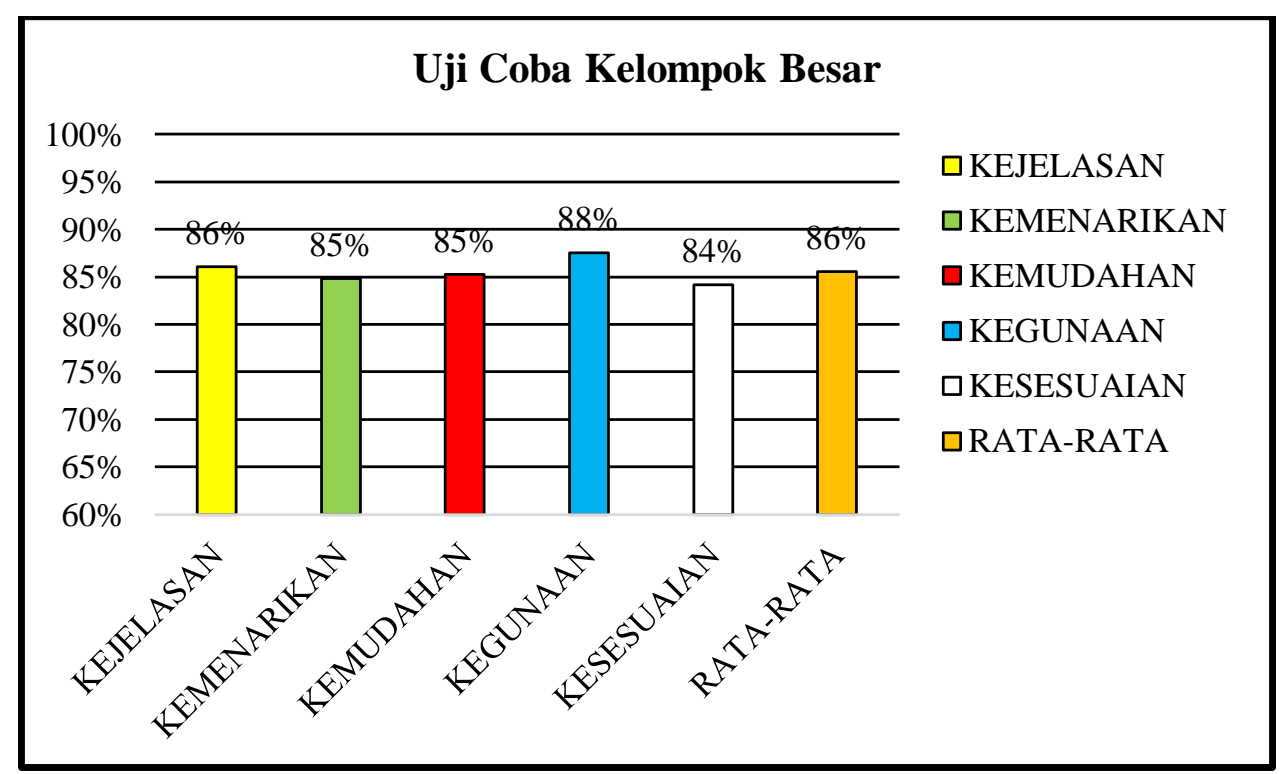

Gambar 7. Diagram Bagian Uji Coba Kelompok Besar

Bersumber pada hasil menganalisis perolehan data yang didapatkan pada uji coba kelompok besar sebesar $86 \%$, hasil itu diperoleh dengan berlandaskan pedoman-pedoman yang telah dibuat. Tahap selanjutnya dengan mengkonversikan hasil tersebut kedalam tabel kategorisasi kelayakan yang mengindikasikan bahwa produk yang dikembangkan mendapatkan kategori kriteria sangat valid dan layak diimplementasikan dalam pembelajaran.

\section{PEMBAHASAN}

Produk pengembangan ini merupakan ini merupakan pengembangan perangkat pembelajaran bola basket berbasis aplikasi articulate storyline yang dapat diakses melalui smartphone dan laptop. Perangkat pembelajaran merupakan instrumen dari guru ketika melakasanakan kegiatan mengajar. Perangkat pembelajaran yang diciptakan bagi seorang guru haruslah dikembangkan lagi sesuai teknologi yang berkembang pada saat ini. Hasil temuan oleh Hamzah, Mu'arifin, Heynoek, Kurniawan, \& Kurniawan (2020b) menyimpulkan perangkat pembelajaran yang didesain menarik dan mudah dipahami dapat digunakan pendidik dalam mengajar peserta didik.

Pada pengembangan perangkat pembelajaran ini menggunakan aplikasi articulate storyline yang merupakan software yang dapat digunakan dalam menciptakan perangkat pembelajaran dengan cara berinteraksi melalui isi di dalamnya dengan bentuk gabungan teks, gambar, grafik, suara, animasi, dan video. Hasil penelitian oleh Darnawati, Batia, Irawaty, \& Salim (2019) mengatakan software articulate storyline adalah sofware untuk membuat media pembelajaran berbasis teknologi. Hasil temuan juga serupa Nabilah, Sesrita, \& Suherman (2020) menyimpulkan bahwa software articulate storyline layak digunakan dalam mengembangkan berbagai media dan perangkat pembelajaran. Dengan bentuk akhir dari pada produk pengembangan perangkat pembelajaran bola basket berbasis aplikasi articulate storyline ini berupa aplikasi yang dapat diakses melalui smartphone dan laptop yang tentunya sangat memudahkan pendidik dan peserta didik dalam 
menggunakannya. Hasil temuan oleh Pamungkas \& Dwiyogo (2020) menyimpulkan penggunaan mobile learning dapat meningkatkan efisiensi efektifitas pada pembelajaran PJOK.

Dengan keunggulan bentuk akhir dalam produk pengembangan perangkat pembelajaran bola basket berbasis aplikasi articulate storyline ini berupa aplikasi yang dapat diakses melalui smartphone dan laptop yang tentunya sangat memudahkan pendidik dan peserta didik dalam menggunakannya. Kemudian pada aplikasi ini berisi Rencana Pelaksanaan Pembelajaran (RPP), bahan ajar, pada materi bola basket, evaluasi pembelajaran, video pembelajaran, referensi materi dan profil pembuat. Selain itu penelitian oleh R. A. Akbar \& Hariyanto (2020) mengatakan dengan menggunakan bahan ajar berupa multimedia iteraktif dapat meningkatkan hasil belajar dan minat siswa pada pembelajaran PJOK. Hasil temuan juga serupa Budi \& Prihanto (2014) mengatakan penggunaan media dalam kegiatan belajar mengajar pada materi bola basket dapat meningkatkan hasil belajar peserta didik.

Produk pengembangan ini ditekankan pada materi bola basket yang dikembangan sesuai dengan kompetensi dasar kelas VI Sekolah Dasar. Produk ini dapat dipakai sebelum melakukan kegiatan praktik pada kegiatan pembelajaran. Pada video pembelajaran terdapat variasi dan kombinasi yang meliputi gerak dasar lokomotor, nonlokomotor, dan manipulatif pada permainan bola basket. Pada video yang terdapat didalamnya nantinya dapat memudahkan guru PJOK dalam menyampaikan materi ajar bola basket dikarenakan telah sesuai dengan kompetensi dasar.

Dengan harapan dalam melaksanakan pembelajaran materi bola basket lebih beragam dalam usaha memperoleh hasil belajar peserta didik yang maksimal dan menambah referensi pendidik ketika melakukan pembelajaran di sekolah pada mata pelajaran PJOK materi bola basket kelas VI Sekolah Dasar.

\section{KESIMPULAN}

Kesimpulan dari penelitian dan pengembangan ini ialah, produk pengembangan perangkat pembelajaran bola basket berbasis aplikasi articulate storyline yang dikembangkan peneliti yang berisi RPP, bahan ajar, video pembelajaran, dan soal evaluasi layak digunakan dalam pembelajaran PJOK pada tingkat sekolah dasar kelas VI. Produk ini nantinya dapat memudahkan guru nantinya dalam menyampaikan materi kepada peserta didik.

\section{DAFTAR PUSTAKA}

Adi, S., \& Fathoni, A. F. (2019). Development of Learning Model Based on Blended Learning in Sports School. https://doi.org/10.2991/acpes-19.2019.2

Adi, S., \& Fathoni, A. F. (2020a). Blended Learning Analysis for Sports Schools in Indonesia. International Journal of Interactive Mobile Technologies (iJIM), 14(12), 149-164. Retrieved from https://www.onlinejournals.org/index.php/i-jim/index

Adi, S., \& Fathoni, A. F. (2020b). Mobile Learning sebagai Fasilitas Belajar Mandiri Pembelajaran Senam Lantai pada Mahasiswa Jurusan IImu Keolahragaan. Jurnal Pendidikan: Teori, Penelitian, Dan

Pengembangan, 5(8), 1158-1166. Retrieved from http://journal.um.ac.id/index.php/jptpp/article/view/13946/6206

Adi, S., \& Fathoni, A. F. (2020c). The effectiveness and efficiency of blended learning at sport schools in Indonesia. International Journal of Innovation, Creativity and Change.

Akbar, R. A., \& Hariyanto, E. (2020). Pengembangan Bahan Ajar Pencak silat Untuk Siswa Sekolah Dasar. Sport Science and Health, 2(7), 350-356. Retrieved from http://journal2.um.ac.id/index.php/jfik/index

Akbar, S., \& Sriwiyana, H. (2011). Pengembangan Kurikulum dan Pembelajaran Ilmu Pengetahuan (IPS). Malang: Cipta Media.

Andri, R. M. (2017). Peran dan Fungsi Teknologi Dalam Peningkatan Kualitas Pembelajaran. Jurnal Ilmiah Research Sains, 3(1), 122-129.

Bangun, S. Y. (2016). Peran Pendidikan Jasmani Dan Olahraga Pada Lembaga Pendidikan di Indonesia. Publikasi Pendidikan, 6(3). https://doi.org/10.26858/publikan.v6i3.2270 
Budi, B. A. S., \& Prihanto, J. B. (2014). Penggunaan Media Audiovisual Dengan Media Gambar Terhadap Hasil Belajar Shooting Bola Basket. Jurnal IImiah Pendidikan Jasmani Olahraga Dan Kesehatan, 2(3), 612-616.

Christianto, J., \& Dwiyogo, W. D. (2020). Pengembangan Media Pembelajaran Cricket Berbasis Mobile Learning Pada Tim Olahraga Cricket Universitas Negeri Malang. Gelanggang Pendidikan Jasmani Indonesia, 3(2), 168. https://doi.org/10.17977/um040v3i2p168-174

Darnawati, Batia, L., Irawaty, \& Salim. (2019). Pemberdayaan Guru Melalui Pengembangan Multimedia Pembelajaran Interaktif Dengan Aplikasi Articulate Storyline. Jurnal Pengabdian Kepada Masyarakat, 1(1), 8-16.

Fathir, L. W., \& Tuasikal, A. R. S. (2013). Pemanfaatan Media Computer Assisted Instructional (CAI) Model Drills Pada Materi Ajar Travelling Violation Permainan Bola Basket. Jurnal Pendidikan Olahraga Dan Kesehatan, 1(1), 247-251.

Fathoni, A. F. (2018). The Role of Blended Learning on Cognitive Step in Education of Sport Teaching by Adjusting the Learning Style of the Students. https://doi.org/10.2991/isphe-18.2018.49

Fitron, M., \& Mu'arifin. (2020). Survei Tingkat Persepsi Siswa Terhadap Konsep Pendidikan Jasmani Di Sekolah Menengah Atas. Sport Science and Health, 2(5), 264-271.

Hamzah, H., Mu'arifin, M., Heynoek, F. P., Kurniawan, R., \& Kurniawan, A. W. (2020a). Pengembangan Perangkat Pembelajaran Model Discovery Learning Materi Gerak Lokomotor Kelas Rendah Sekolah Dasar. Sport Sciences for Health, 2(8), 384-394. Retrieved from http://journal2.um.ac.id/index.php/fik/article/view/11629

Hamzah, Mu'arifin, Heynoek, F. P., Kurniawan, R., \& Kurniawan, A. W. (2020b). Pengembangan Perangkat Pembelajaran Model Discovery Learning Materi Gerak Lokomotor Kelas Rendah Sekolah Dasar. Sport Science and Health, 2(8), 384-394.

Kristiono, I. D., Dwiyogo, W. D., \& Hariadi, I. (2019). Pembelajaran IImu Gizi Olahraga Berbasis Blended Learning pada Mahasiswa Pendidikan Jasmani, Kesehatan, dan Rekreasi. Jurnal Pendidikan: Teori, Penelitian, Dan Pengembangan, 4(2), 235-241. Retrieved from http://journal.um.ac.id/index.php/jptpp/article/view/12004

Kurniawan, R., Winarno, M. E., \& Dwiyogo, W. D. (2018). Evaluasi Pembelajaran Pendidikan Jasmani, Olahraga, dan Kesehatan pada Siswa SMA Menggunakan Model Countenance. Jurnal Pendidikan: Teori, Penelitian, Dan Pengembangan, 3(10), 1-12. Retrieved from http://journal.um.ac.id/index.php/jptpp/article/view/11599

Masgumelar, N. K., Dwiyogo, W. D., \& Nurrochmah, S. (2019). Modifikasi Permainan menggunakan Blended Learning Mata Pelajaran Pendidikan Jasmani, Olahraga, dan Kesehatan. Jurnal Pendidikan: Teori, Penelitian, Dan Pengembagan, 4(7), 979-986. Retrieved from http://journal.um.ac.id/index.php/jptpp/article/view/12645

Miftah, M. (2013). Fungsi, Dan Peran Media Pembelajaran Sebagai Upaya Peningkatan Kemampuan Belajar Siswa. Jurnal Kwangsan, 1(2), 95. https://doi.org/10.31800/jtpk.v1n2.p95--105

Mu'arifin, M. (2019). Problem Identification of Professional Development of Physical Education Teachers in Elementary School. https://doi.org/10.2991/icssh-18.2019.32

Mu'arifin, Kurniawan, A. W., \& Paulina, F. (2018). Developing Professional Development Model For Physical Education, Sports, and Health Primary School Teachers in Learning Organizing. Journal of Indonesian Physical Education and Sport, 4(2), 79-80. https://doi.org/http://journal.unj.ac.id/unj/index.php/Jipes

Mufidah, A. (2018). Peningkatan Kompetensi Pedagogik Guru Dalam Menyusun Perangkat Pembelajaran Melalui Workshop KKG Mini Di SDN Sepande Kecamatan Candi Kabupaten Sidoarjo. Jurnal Mitra Pendidikan, 2(1), 11-22.

Munawaroh. (2020). The influence of problem-based learning model as learning method, and learning motivation on entrepreneurial attitude. International Journal of Instruction, 13(2), 431-444. https://doi.org/10.29333/iji.2020.13230a 
Nabilah, C. H., Sesrita, A., \& Suherman, I. (2020). Development Of Learning Media Based On Articulate Storyline. Indonesian Journal of Applied Research, 1(2), 80-85.

Pambudi, M. I., Winarno, M., \& Dwiyogo, W. D. (2019). Perencanaan dan Pelaksanaan Pembelajaran Pendidikan Jasmani Olahraga Kesehatan. Jurnal Pendidikan Olahraga, Universitas Negeri Malang, 4(1), 110-116. Retrieved from http://journal.um.ac.id/index.php/jptpp/

Pamungkas, I. A., \& Dwiyogo, W. D. (2020). Pengembangan Media Pembelajaran Berbasis Mobile Learning Untuk Aktifitas Kesegaran Jasmani Siswa kelas X Sekolah Menengah Kejuruhan. Sport Science and Health, 2(5), 272-278. Retrieved from http://journal2.um.ac.id/index.php/ffik/article/view/11828/5768

Rakhman, A., \& Brata, Y. R. (2018). Pengaruh Kompetensi Pedagogik dan Kelompok Kerja Guru ( KKG ) Terhadap Kinerja Guru Pendidikan Jasmani Olahraga. Indonesian Journal of Education Management and Administration Review, 2(2), 259-264.

Rodriquez, E. I. S., Dwiyogo, W. D., \& Supriyadi. (2020). Blended Learning Matakuliah Sepakbola untuk Mahasiswa Pendidikan Jasmani Kesehatan dan Rekreasi. Jurnal Pendidikan: Teori, Penelitian, Dan Pengembagan, 5(2), 206-213.

Soeprapto, S. (2013). Landasan Aksiologis Sistem Pendidikan Nasional Indonesia Dalam Perspektif Filsafat Pendidikan. Cakrawala Pendidikan, (2), 266-276.

Sugiyono. (2015). Metode Penelitian Pendidikan. Bandung: Alfabeta.

Walton, E. P., \& Lismadiana, L. (2015). Pengembangan Model Pembelajaran Bola Basket Bagi Anak Sd Kelas Atas. Jurnal Keolahragaan, 3(1), 29-38. https://doi.org/10.21831/jk.v3i1.4967

Yayuk, E., \& Prastiyowati, S. (2019). Pendampingan Pembuatan Perangkat Pembelajaran Kurikulum 2013. International Journal of Community Service Learning, 3(4), 222. https://doi.org/10.23887/ijcsl.v3i4.21793 